\title{
Geological Parks, Eco-tourism and Sustainable Development
}

\author{
Jian-Xinog Qin \\ Institute of Regional Geography \&Tourism Development, Southwest University for Nationalities, Chengdu, China \\ E-mail: jx-qin@vip.163.com
}

\begin{abstract}
Based on the comparative analysis of the definition of geological parks, ecological tourism and sustainable development, this paper discusses the dialectical relationship between the geological parks, ecological tourism and sustainable development. The geological park is an important part of the ecological tourism resources, and the geological park is an important place and an ideal place for the development of eco-tourism. Geological park and ecological tourism development has a similar goal system, development characteristics, development principles and contents. Geological park is an important part of the theory of sustainable development, is the embodiment of sustainable tourism. The tourism development of geopark is a concrete manifestation of ecological tourism, sustainable tourism development principle. Therefore, both in function and purpose is consistent, Geopark geological popular science tourism based on greatly improve and enrich the grade and content of ecological tourism, ecological tourism is strategic choice of sustainable development of geological park.
\end{abstract}

Keywords-Geological Park; Eco-tourism; Sustainable development

\section{GEOLOGICAL PARKS AND ECOLOGICAL TOURISM}

UNESCO definition of geological park contains the following features: regional scope clear set of rare and precious ornamental, and has special scientific significance as one of several geological relics or geological aggregate, both geological and archaeological, ecological, historical and cultural value; emphasizing the development of geological heritage national geological park the protection and the local economy, combining the development and production of information education of the Geopark, geological relics protection and geological research combination; strengthen the protection of the ecological environment, pay attention to the value of the global public awareness, improving human knowledge and ability of the earth's crust and its rational utilization, trying to maintain the balance between human and earth.

Definition of ecotourism at home and abroad a lot, but nevertheless included almost all the following three functions: appreciation, enjoy the high quality of the tourism experience, including the beautiful natural environment and unique humanistic culture; protection of natural and cultural ecological system, strengthen the protection of the ecological environment, attach importance to public awareness of ecological value; to promote the sustainable development of regional economy.
From the definition we can see, both in function and purpose is consistent, and emphasize the following three binding: combination of local economic development and the protection of natural and cultural ecological system; appreciate the nature and know the combination of nature; protection ecological environment and widespread public awareness of protection combined.

\section{II.THE RELATIONSHIP BETWEEN THE GEOLOGICAL PARK AND ECOLOGICAL TOURISM}

\section{A. Geological relic resource is an important part of the ecological tourism resources}

From the characteristics of resources, geological heritage resources and eco-tourism resources have similar inherent characteristics, but also have its own unique characteristics, mainly in the:

(1) Nature of the geological heritage. Geological relics are in the long geological processes of the evolution of the earth, due to inner earth and exogenic process and the formation, development and the legacy of the precious, non renewable natural geological heritage, in particular to a variety of geological relic resources, showing obvious geological natural heritage properties.

(2) Ecological beauty and ornamental. Geological heritage resources is the nature after billions of years of a long evolution, life and local environment running, in addition to the sensory feast for the eyes, it is rich in science, aesthetics, philosophy and culture connotation attract tourists.

(3) Vulnerability and protection. Vulnerability refers to the limited capacity of geological heritage resources system for the development of the external disturbance. From the perspective of tourism development, it is not known that the vulnerability of the geological heritage resources will cause damage to the geological heritage resources system. For the sustainable utilization of geological relic resources, it is necessary to follow the natural law of geological relics. In the development, we should adhere to the principle of protective development.

(4) Non portability. Geological heritage resources are the gifts of nature, which are formed under the specific natural geological conditions, the characteristics of the formation, the ecological environment and tourism functions are unique can not be copied and can not be transplanted.

(5) Development and utilization of sustainability and vulnerability. According to the nature and characteristics of tourism development and utilization, it is sustainable utilization of geological heritage resources. However, due to its ecological vulnerability and environmental sensitivity, 
geological heritage resources can not be used to destroy the ecological balance of the system due to improper use. The sustainable development can only be realized only under the condition of moderate exploitation and protection of geological heritage resources.

(6) Comprehensive and systematic. Comprehensive refers to the geological relic resources by the related factors of geology, geomorphology, climate, environment, terrain consisting of a complex; system is interconnected, interdependent and mutually restricted relationship exists between each part of the system of geological heritage resources and internal. In this system there is a inherent geological ecological structure and energy flow, information flow and material circulation, to disrupt and destroy any external conditions will lead to the change of the system.

(7) Diversity and universality. Geological heritage resources, with its diversity and universality, are inferior to other tourist resources. Mainly displays in: first, the geological heritage resources in the space of a wide range of time on the broad and extensive content.

\section{B. The geological park is an important place for the development of ecological tourism and an ideal place for the development of the ecological tourism}

Geopark is to protect as the premise, the use of the multiple functions of geological relic resources for tourists to provide various forms of tourism services, and scientific and cultural activities of regional economy management, it sets the typical, representative, rarity, natural, systematic, complete and scientific research value in one. The guiding ideology of the development and planning of the geological park is: Taking the landscape resources as the main body, making full use of various natural and cultural tourism resources, under the premise of the protection of the reasonable planning, moderate development. The aim is to realize the unity of the three of the social benefit, environmental benefit and economic benefit through the development, construction, operation and management of tourism.

And other national parks, nature reserves, scenic area, forest park, county-level city, the Provincial Geological Park especially national and world-class geological park, as a common natural heritage of mankind, is to carry out ecological tourism and an important foundation of the ideal place, and is in the framework of the ecological tourism plays a more and more important role.

\section{Geological park development and ecological tourism similar to the target system}

Geological Park as an open complex whole which is composed geological system, protection system and tourism system of three subsystems (Figure 1). Geological system refers to the special scientific significance, rare natural quality and elegant aesthetic value of the geological heritage landscape as the main body. Protection system refers to the laws, regulations and specific measures for the protection of geological relics. Tourism system is a development system, which includes three subsystems: destination system, market system and service system.
Geopark tourism development has a similar goal system and ecological tourism. Mainly promote local economic development in three aspects, provide high quality tourism experience and the protection of geological heritage

Realization of geopark tourism sustainable development, correctly handle the dialectical relationship between the development and protection of geological heritage resources, should firmly grasp the "people" the important controlling factors and "leading role", and actively promote community visitors - Enterprise - state cooperation in the protection, development and scientific management ideas. Fully reflects the government (Management), research and planners (technical support), tourists (tourist body layer), business (Management), community residents (in layer) related to the interests of the layer between coordination and the division of labor relations.

\section{As an important form of eco tourism, the development of the geological park has the similar content as the ecological tourism development planning.}

The development of Geopark planning is complicated system engineering. Is not only related to the interests of the various interest groups, also relates to the local economy, resources, social and environmental factors. Therefore, it is necessary to government agencies, social organizations and the public to participate in a wide range of cooperation, need to travel, destination travel community and who assist in separation. Aggregation of geology, geomorphology, structural geology, tourism science, ecology, biology, geography, environmental science, landscape architecture, economics, humanities etc. multidisciplinary expert participation, complementary advantages, effectively develop overall consideration of the development planning of society as a whole and long-term interests.

According to the working guidelines for the overall planning of Geological Park (trial, 1999), geological park planning includes the basic content of the following aspects: (1) Geological Park local natural and social conditions and social economic situation and the historical evolution; (2) the Geological Park Tourism Analysis and other industry development status; (3) the tourism geological resources of regional geology general situation, and other tourism resources distribution, classification and evaluation; (4) the geological park planning basis and principle; (5) the nature, scope and overall layout of geological park; (6) analysis, planning and promotion of Geopark tourist market; (7) the design of Geopark tourism products, project design and tourism; (8) the main geological tourism scenic area (spot) planning; (9) geological relics protection classification planning; (10) ecological environment protection planning; (11) infrastructure planning Service facilities planning, communication planning, popular science interpretation planning and safety and health planning; (12) organization and management planning; (13) the investment budget and the development and construction sequence. 


\section{DIALECTICAL RELATIONSHIP BETWEEN GEOLOGICAL PARKS AND SUSTAINABLE DEVELOPMENT}

\section{A. The geological park is an important part of the theory of sustainable development, and it is the concrete embodiment of the sustainable tourism.}

Tourism development of geological parks is a has a specific purpose and geological nature oriented tourism form, is a both protection and development of natural purpose, is to achieve sustainable tourism a way and method, the principle of sustainable tourism in geological natural areas and specific agency will be the concrete practice and practice of regional culture. It has the general characteristics of the ecological tourism.

A Geopark geological heritage, ecological environment and cultural environment, the original geological and nature, which includes three aspects: one is the regional tourism tourists to the unique geological landscape, natural scenery, the population is relatively scarce, the influence degree of industrialization is low, a relatively pristine ecological preservation the environment; two is that the region has a unique geological history and culture, the life style and cultural patterns of the original state of pure natural reserve system, has the psychological cultural allure for tourists; three is the design of the special tourism projects and in line with the above two requirements for the content, reflect the specific characteristics of the ecological environment of Geological Tourism the relative concentration of the natural and geographical conditions, harmonious and humanistic conditions deposit requirements.

The protection of geological tourism geological park is mainly reflected in the following aspects: one is based on the development of tourism planners to comply with the ecological law of geological nature, design manifests the human and the natural harmony of geological green tourism products unified; two is the tourism developers to fully realize the economic value of geological relic resources, the resource value into cost accounting three; tourism management is to fully understand the environmental geology resources capacity range and bearing capacity for sustainable tourism, the three major benefits of coordinated development; four is the tourists to improve their environmental awareness and quality in tourism, cherish nature of human material and spiritual values, the protection of geological resources and environment has become a conscious behavior.

Geological tourism is a kind of special form different from the traditional mass tourism activities; it has certain requirements for tourists and tourism management. The plan of geological tourism is in small scale, low density, dispersion and professional. Professional geological tourism shows: tourists consciously protect the geological heritage resources and natural ecological environment, professional tourism management in the development planning and management process.

As a result of the specific historical condition of geological park and its tourism development and related geological tourism and other ecological tourism, with high grade, mainly in: 1) the geological relic resources and related geological park special causes of geological tourism professional and high grade of; 2) geological heritage resources and geological park properties caused by the attraction of high grade tourist bias; 3) the particularity of geological relic resources and geological park of tourism development and management of high grade, high quality requirements; 4) Geological Park professional castigate local residents quality and grade of the promotion.

On the one hand, the geological tourism can let the tourists who were personally involved in natural and cultural ecological system, in the actual experience of understand the mysteries of the geological, ecological tourism, to love more geological relics and natural ecology, which is conducive to the protection of tourism resources and the environment. On the other hand, geological tourism, as a special form of eco-tourism, is a kind of tourism activity which is widely used by tourists, residents, tourism operators and government, community organizations and researchers.

\section{B. Geological park tourism development is the embodiment of the ecological tourism, with the principle of sustainable tourism development}

The geological park is an ideal place for the practice of ecological tourism, the geological park in the development of tourism; it should follow the principles of sustainable development guiding ideology and ecological development.

To meet the development needs of geological heritage resources as the premise, not only to maintain the original style of the resources, but also to maintain the balance of resources and ecological system development principles. In the specific application, the principle can be realized through a number of specific measures, such as environmental bearing capacity design, reduce the use of private transport, tourist flow control and adjustment, tourism facilities construction control and people's environmental awareness, improve and.

To make sustainable use of the geological park, it is necessary to strengthen the protection of geological heritage resources. The general principle for the development and protection of the relationship is that the development should be subject to protection under the premise of protection. Resources are properly protected; development to get benefits, in turn, to promote the protection of work.

A Geopark geological heritage resource, the difference lies in: geological process of the long and complexity, the original and natural, typical and rare, beautiful and non renewable, and the distribution of the remote nature and relevant local and national. It is these characteristics that constitute the attractiveness and competitiveness of the geological park. Therefore, in the tourism development, not only to highlight and maintain its natural features and the original style, to show the power of the geological nature of the seven wonders of the. At the same time, but also make its characteristics more distinctive and development, and can not be developed, so that the characteristics of damage.

The development of geological relic resources must be coordinated with the environment of the whole geological ecological area. Geological park tourism development if we 
can harmonize with the surrounding ecological and cultural environment is conducive to highlight the characteristics of the geological heritage landscape, can form the integral beauty of rapid tourism resources, make tourists feel comfortable, natural. Therefore, geological tourist routes and facilities construction planning to do not destroy the geological vestiges landscape, do not pollute the environment, does not affect the species to survive and reproduce, protect and maintain the security and integrity of the geological and ecological system.

It is the unity of economic benefit, social benefit and environmental benefit. This is a geological park tourism development, is also the starting point and goal of eco-tourism. The general embodiment is that economic interests should be subject to the social and environmental benefits, and the realization of economic goals must be based on the premise that the ecological environment is not damaged.

\section{CONCLUSIONS}

The introduction of the last century 80's nascent tourism concept has opened a new page of world tourism. Ecological tourism has attracted universal attention of all countries in the world, and with the rapid speed to replace the traditional travel way into people's real life, which deserves to be commander in chief of the development of the entire tourism industry.

Geological popular science tourism in China is also raising in the early 80's, the thirtieth International Geological Congress in 1996 to develop a number of tourist routes to set off the first upsurge of geological science tourism. In the United Nations education, scientific and Cultural
Organization (UNESCO) "World Geological Park" plan to promote, in order to with the fully in line, the Ministry of land and resources on March 16, 2001 approved the establishment of the first batch of National Geological Park 11 , which in the history of geological heritage protection can not be said to have epoch-making significance! Thus once again set off the climax of the geological popular science tourism. Along with the establishment and development of the geological park, the geological popular science tourism based on the geological park is an important way to develop the ecological tourism as the popular science tourism and forest tourism. Geological science tourism has greatly improved and enriched the grade and content of ecological tourism; ecological tourism is a strategic choice for sustainable development of geological park. It is the only way for the sustainable development of the Geo Park to carry out the eco tourism, protect and develop each other in the geological park.

\section{ACKNOWLEDGEMENT}

This research was financially supported by the National Natural Science Foundation.

\section{REFERENCES}

[1] Alexis Saveriades. "Establishing the social tourism carrying capacity for the tourist resorts of the east coast of the Republic of Cyprus". Tourism Management, Vol. 21, Issue 2, pp. 147-156, Apr. 2000.

[2] Sasicha Sukkay, Nopadon Sahachaisaeree, "A Study of Tourists' Environmental Perceptions of the Functional Design of Popular Resorts in Chiang Rai Province". Procedia-Social and Behavioral Sciences, vol.50, pp.114-122, May, 2012. 